\title{
Interactions between person's cognition, food and biological processes over multidisciplinary intervention
}

\author{
Maša Černelič Bizjak*, Mojca Bizjak and Zala Jenko-Pražnikar \\ University of Primorska, Faculty of Health Sciences, Slovenia
}

\begin{abstract}
The aim of the present study was to explore interactions between food, cognition and biological processes in relation to health. Therefore, we assessenergy intake, total fat, protein and carbohydrate intake and negative cognition about body image and inflammation biomarkers over 6-month multidisciplinary intervention. The participants were evaluated at baseline and after the 6-month of intervention. 33 overweight and 33 obese adults completed a 6-month intervention trial to evaluate the effects of an individual dietary programme based on individual's resting metabolic rate on anthropometry, metabolic profile, and inflammation. Pearson's correlations were performed to investigate the possible associations between reductions in obesity, inflammation, dietary intakes with decrease in body dissatisfaction.Furthermore, hierarchical multiple regression analyses revealed that relative changes in obesity indicators accounted for $23 \%$ of the variation in reduction of inflammation biomarker $\mathrm{C}$ - reactive protein, changes in composition of diet $13 \%$ of variation and changes in negative cognition explained an additional $8 \%$ of the variation in inflammation level of CRP. Together the independent variables accounted for $44 \%$ of the variance in inflammation level of CRP. The important findings of the present study were that reduction in carbohydrate intake and increase in protein intake in diet, with more positive cognition about body image,significantly predicted a reduction in level of inflammation biomarker, measured with CRP. Changes in energy intake and total fat intake and physical activity did not predicted reduction of inflammation.
\end{abstract}

\section{Introduction}

Society is increasingly confronted with chronic diseases which have been shown to be related with obesity, unhealthy lifestyle and eating habits [1]. The new challenge is to understand interactions between biological processes and food with person's cognitions in relation to health. Most of studies report that "Western-like" dietary patterns tended to be positively associated with biomarkers of inflammation, predominantly CRP $[2,3]$ and that some lifestyle changes and uptake of healthy diet [4] are effective in reducing inflammation. On the other hand, some cognitive factors have great impact on person's behaviour. Negative cognitions relating to body image dissatisfaction are linked with many unhealthy behaviour [5],-including a poor prognosis to lose weight, physical inactivity and with a broad range of disordered eating [6]. Importantly, recent research [7] demonstrated that body dissatisfaction uniquely predicted the levels of biomarkers, even when controlled for obesity indicator. These novel findings underlay the importance to focus on the potential modifying factors in association between food and inflammation, on cognitions which are also related to health [7]. The aim of the present study was to explore interactions between food, cognition and biological processes in relation to health. Therefore, we assess energy intake, total fat, protein and carbohydrate intake and negative cognition about body image and inflammation biomarker CRP over 6-month multidisciplinary intervention.

\section{Methods}

\section{Participants}

33 overweight or obese adults ( 20 female, 13 male) were enrolled to 6-month obesity treatment program. The mean age of participants was
38.9 years ( $\mathrm{SD}=6.5$ year). Twenty of them were overweight $(\mathrm{BMI}>25)$ and thirteen obese $(\mathrm{BMI}>30)$.

\section{Measurement}

Participants were evaluated at baseline and after the 6-month of obesity treatment program to discover the effects of an individual dietary programme on anthropometry, inflammation and body image dissatisfaction. Participants underwent a comprehensive series of physical and psychological, and nutritional, biochemical evaluations prior to treatment.All examination methods and procedures followed standard manual operations and were measured using a standardized protocol.

\section{Resting metabolic rate}

A hand-held indirect calorimeter (MedGem * Microlife) from Medical Home Solutions, Inc., Golden, $\mathrm{CO}$ was used for measuring RMR. All RMR measurements were performed between 7 A.M. and 8 A.M., after eight hours of sleep. Measurements were carried out after auto calibration of the device in a quiet thermo-neutral environment (20 to $22^{\circ} \mathrm{C}$ ).

Correspondence to: Maša Černelič Bizjak, University of Primorska, Faculty of Health Sciences, Polje 42, SI-6310 Izola, Slovenia; Tel: (00386) 05-662-6469; E-mail: masa.cernelic@fvz.upr.si

Key words: energy intake, obesity, inflammation

Received: November 20, 2014; Accepted: December 23, 2014; Published: January 03, 2015 


\section{Anthropometric measurements}

All measurements were performed between 7 A.M. and 9 A.M. in standardized conditions by the same examiner after fasting overnight. At the study site height, weight and waist circumference were measured using a standardized protocol. Subject height was measured to the nearest $0.1 \mathrm{~cm}$ in a standing position, without shoes, using Leicester Height Measure (Invicta Plastics Limited, Oadby, England). Body weight of the participants wearing usual light indoor clothing without shoes was measured with a $0.1 \mathrm{~kg}$ precision. Waist was measured in standing position halfway between costal edge and iliac crest, whereas hip was measured as the greatest circumference around the buttocks. BMI was calculated using the formula: weight $(\mathrm{kg}) / \mathrm{height}\left(\mathrm{m}^{2}\right)$. Body composition (total percentage body fat $(\% \mathrm{BF})$ and percentage trunk fat $(\% \mathrm{TF})$ ) was assessed by using bioelectrical impedance analysis (BIA) Tanita BC 418MA (Tanita Corporation, Arlington Heights, IL) and data analyzed with the software provided by the same producer.

\section{Pearson's cognition about body}

Body satisfaction (a subjective parameter of body image) was assessed as a cognitive aspect of a person's concept about his/her body. We used three items that focused on the most relevant aspects for the particular appearance concerns of obese individuals, and that have been used in previous studies [8]. Participants answered questions on satisfaction, which were to be answered according to a 5-point response scale ranging from 1 (completely satisfied), to 5 (not at all), such that higher scores indicated greater dissatisfaction.

\section{Serum analyses}

Venous blood samples for biochemical and hormonal determinations were collected in the fasting state in the morning between 7 A.M. and 9 A.M. (in standardized conditions) in $4 \mathrm{~mL}$ vacuum test tubes (Beckton-Dickinson, Rutherford, USA). Serum was immediately separated, frozen and stored at $-20^{\circ} \mathrm{C}$ until subsequent analysis. The biochemical analyses have already been described [9]. Serum concentrations C-reactive protein (CRP) were measured using Olympus reagents and performed on an AU 680 analyzer (Beckman Coulter) [10].

\section{Food record}

At baseline, subjects were instructed to record their food intake for three consecutive days (two weekdays and one day during the weekend) the week before blood samples were taken for biochemical analyses. Where possible, subjects were asked to include food labels and recipes for mixed dishes and were encouraged to avoid any alterations to their normal diet. All food records (FR) were checked and completed by dieticians if unclear descriptions or a lack of data became evident. Nutrient composition was analyzed using the Open Platform for Clinical Nutrition (OPEN) program that is accessible through the website http://opkp.si/. Data from FRs were automatically converted into energy intake and nutrients, namely protein, carbohydrates, fibre, total fatty acid, saturated fatty acid (SFA), monounsaturated fatty acid (MUFA), and polyunsaturated fatty acid (PUFA).

\section{Intervention}

\section{Diet plan intervention in small groups, in-person training and individual diet plan intervention}

The 6-month intervention included sessions of individual education about prescribed personalized diet plan and consisted primarily of adopting a moderately energy restricted diet and daily caloric intake and increase in physical activity. Daily energy requirements were calculated from the individual's resting metabolic rate (RMR) and physical activity level factor, with a moderate energy restriction of $2100 \mathrm{~kJ}$ ( $500 \mathrm{kcal})$.All subjects attended two educational sessions about healthy diet, nutritional composition; correct timing of eating and about the beneficial effects of daily vegetable and fruit eating. Each group included 6-7 subjects. In addition, all subjects attended two sessions of individual education about their prescribed individual diet plan (each subject was given a personalized diet plan). The goal of our intervention was that each participant loses $2 \mathrm{~kg}$ of weight per month. A weight loss of approximately $2 \mathrm{~kg}$ per month, results from a loss of adipose tissue that entails an energy deficit of $58800 \mathrm{~kJ}(14000 \mathrm{kcal})$ per month. This requires a daily energy deficit of approximately of 2100 $\mathrm{kJ}(500 \mathrm{kcal})$ per day (Seagle et al., 2009). Therefore the reduction of $500 \mathrm{kcal}$ for each participant was made. To estimate total energy needs, individual RMR (person's RMR) measured from indirect calorimeter was multiplied by the appropriate activity factor (from 1.3 to 1.6), than the reduction of $500 \mathrm{kcal}$ for all participants was made, except for two female participants who had very low RMR. In those 2 subjects the restriction of $250 \mathrm{kcal}$ per day was made.

Planned macronutrients were $15-17 \%$ of energy from proteins, $25-30 \%$ of energy from fat and more than $50 \%$ of energy from carbohydrates. Dietary fat composition was less than $10 \%$ of SFA, a least $10 \%$ of MUFA and 5\% of PUFA. They received a list of foods for each meal and the quantity of food in grams from which to choose. No drugs or antioxidants were recommended. All subjects had three weight checking and RMR measurements during intervention, when the diet plan was adjusted.

\section{Statistical analysis}

All analyses were performed using the SPSS statistics version 20.0 (IBM, Chicago, IL). Means and standard deviation of the mean were determined at both baseline and after 6 months of intervention for all parameters. Analysis of the effect of intervention on the variables was conducted using Student's paired $t$-test. These analyses were performed on 6 months outcomes of body composition, dietary intake, physical capabilities, body satisfaction, and metabolic profile. Associationsamong the variables were examined using Pearson correlations.Statistical significance was defined as $p<0.05$. Furthermore, hierarchical approach was performed.

\section{Results}

After intervention, the intervention group showed significant weight loss $(-4 \pm 3.4 \% ; p<0.001)$ and decreases in body image dissatisfaction $(-15 \pm 20.8 \% ; p<0.01)$, with greater improvement among females $(-$ $17 \pm 40 \%$; $p<0.005)$. Significant improvements were observed in all physical related variables (e.g. BMI, percentage of total fat mass, and waist and hip circumference) (Table 1).

Our findings suggest that reduction in BMI and total body fat was independent and most important predictor of changes in inflammatory biomarker. Therefore controlling for weigh status and indicators of obesity and its reduction was essential to determine if changes in 
nutrition intake and body dissatisfaction add anything to the prediction of reduced inflammation.

Hierarchical multiple regression analyses revealed that relative changes in obesity indicators accounted for $23 \%$ of the variation in reduction of inflammation biomarker CRP, changes in composition of diet $13 \%$ of variation and changes in negative cognition explained an additional $8 \%$ of the variation in inflammation level of CRP (Table 2). Together the independent variables accounted for $44 \%$ of the variance in inflammation level of CRP.

\section{Conclusions}

The important findings of the present study were that reduction in carbohydrate intake and increase in protein intake in diet, with more positive cognition about body image, significantly predicted a reduction in level of inflammation biomarker, measured with CRP. Changes in energy intake and total fat intake and physical activity did not predicted reduction of inflammation.

Thus, we observed that in obese and overweight adults, who lost weight and change some nutrition patterns and became more satisfied with their body image, especially biomarker CRP decreased in greater extent, regardless of changes in physical training or change in energy and total fat intake.

In future studies is important to explore and take into account interactions between food, person's cognition and biological processes in relation to health, with the overall aim to personalize medicine and intervention.

\section{References}

1. Egger G, Dixon J (2014) Beyond obesity and lifestyle: a review of 21 st century chronic disease determinants. Biomed Res Int 2014: 731685. [Crossref]

2. Galland L (2010) Diet and inflammation. Nutr Clin Pract 25: 634-640. [Crossref]

3. Barbaresko J, Koch M, Schulze MB, Nöthlings U (2013) Dietary pattern analysis and biomarkers of low-grade inflammation: a systematic literature review. Nutr Rev 71: 511-527. [Crossref]

Table 1. Anthropometric, psychological, biochemical and physical characteristics of the overweight participants before and after six months of interventiona.

\begin{tabular}{|c|c|c|c|c|c|}
\hline \multirow[b]{2}{*}{ Variable } & \multicolumn{2}{|c|}{$\begin{array}{c}\text { Before intervention } \\
\qquad(n=33)\end{array}$} & \multicolumn{2}{|c|}{$\begin{array}{c}\text { After intervention } \\
(\boldsymbol{n}=\mathbf{3 3})\end{array}$} & \multirow[b]{2}{*}{$p$} \\
\hline & $M$ & SD & M & SD & \\
\hline \multicolumn{6}{|l|}{ Demographics } \\
\hline Gender (men/female) & \multicolumn{2}{|c|}{$20 / 13$} & \multicolumn{2}{|c|}{$20 / 13$} & ns \\
\hline Age (years) & 38.9 & 6.5 & 39.7 & 6.5 & ns \\
\hline \multicolumn{6}{|l|}{ Biological factors } \\
\hline Weight $(\mathrm{kg})$ & 86.5 & 11.8 & 83.1 & 11.4 & $<0.001$ \\
\hline BMI $\left(\mathrm{kg} / \mathrm{m}^{2}\right)$ & 29.4 & 2.7 & 28.2 & 2.6 & $<0.001$ \\
\hline Waist circumference $(\mathrm{cm})$ & 95.2 & 8.3 & 90.9 & 8.4 & $<0.001$ \\
\hline Hip circumference $(\mathrm{cm})$ & 106.7 & 7.9 & 103.2 & 6.9 & 0.006 \\
\hline Body fat mass $(\%)$ & 32.7 & 7.6 & 31.4 & 8.1 & 0.009 \\
\hline \multicolumn{6}{|l|}{ Main variables } \\
\hline $\mathrm{CRP}(\mathrm{mg} / \mathrm{l})$ & 3.02 & 3.00 & 2.26 & 1.79 & 0.026 \\
\hline Body dissatisfaction & 3.88 & 0.96 & 3.30 & 1.16 & 0.005 \\
\hline \multicolumn{6}{|l|}{ Health related behaviours } \\
\hline Physical activity (MET/day) & 2.60 & 2.22 & 3.56 & 2.24 & 0.032 \\
\hline Energy intake (kcal) & 2090 & 690 & 1703 & 750 & $<0.001$ \\
\hline Protein intake (g/day) & 85 & 36 & 73 & 34 & 0.008 \\
\hline Total fat intake (g/day) & 78 & 29 & 63 & 30 & 0.001 \\
\hline Carbohydrate intake (g/day) & 252 & 95 & 202 & 82 & 0.003 \\
\hline
\end{tabular}

Table 2. Multiple regression analysis predicting changes in inflammation, measured with CRP.

\begin{tabular}{|l|c|c|c|}
\hline & \multicolumn{3}{|c|}{ Dependent variable } \\
\hline Predictors & \multicolumn{3}{|c|}{$\Delta$ CRP } \\
\hline Step 1 & $\Delta R^{2}$ & $\beta$ & $F$ \\
\hline \multicolumn{1}{|c|}{ BMI } & $0.23^{* *}$ & & 3.7 \\
\hline \multicolumn{1}{|c|}{ BF } & & $0.42^{*}$ & \\
\hline Step 2 & 0.13 & $0.17^{* * *}$ & \\
\hline \multicolumn{1}{|c|}{ Energy intake } & & & 3.1 \\
\hline \multicolumn{1}{|c|}{ Total fat intake } & & 0.28 & \\
\hline$\Delta$ Protein intake & & $-0.35^{*}$ & \\
\hline$\Delta$ Carbohydrate intake & & $0.24^{*}$ & \\
\hline$\Delta$ Physical activity & & -0.14 & \\
\hline Step 3 & $0.08^{*}$ & & 2.1 \\
\hline \multicolumn{1}{|c|}{ Dissatisfaction with weight } & & $0.24^{*}$ & \\
\hline Total $R^{2}$ & $0.44^{*}$ & & \\
\hline$N$ & 33 & & \\
\hline
\end{tabular}

4. Ahluwalia N, Andreeva VA, Kesse-Guyot E, Hercberg S (2013) Dietary patterns, inflammation and the metabolic syndrome. Diabetes Metab 39: 99-110. [Crossref]

5. Grogan S (2006) Body image and health: contemporary perspectives. J Health Psychol 11: 523-530. [Crossref]

6. Wade TD, Zhu G, Martin NG (2011) Undue influence of weight and shape: is it distinct from body dissatisfaction and concern about weight and shape? Psychol Med 41: 819828. [Crossref]

7. ÄCEerneliÄ-Bizjak M, Jenko-Pra $\AA^{3 / 4} / 4$ ikar Z (2014) Impact of negative cognitions about body image on inflammatory status in relation to health. Psychol Health 29: 264 278. [Crossref]

8. Millstein RA, Carlson SA, Fulton JE, Galuska DA, Zhang J, et al. (2008) Relationships between body size satisfaction and weight control practices among US adults. Medscape J Med 10: 119. [Crossref]

9. Petelin A, Bizjak M, CerneliÄ-Bizjak M, Jurdana M, Jakus T, et al. (2014) Low-grade inflammation in overweight and obese adults is affected by weight loss program. $J$ Endocrinol Invest 37: 745-755. [Crossref]

10. Matthews DR, Hosker JP, Rudenski AS (1985). Homeostasis modelassessment: insulin resistance and beta-cell function from fasting plasma glucose and insulin concentrations in man. Diabetologia 28: 412-419.

11. Seagle HM, Strain GW, Makris A, Reeves RS, American Dietetic Association (2009) Position of the American Dietetic Association: weight management. J Am Diet Assoc 109: 330-346. [Crossref]

12. Dowd JB, Zajacova A (2014) Long-term obesity and cardiovascular, inflammatory, and metabolic risk in U.S. adults. Am J Prev Med 46: 578-584. [Crossref]

Copyright: (C2014 Bizjak MČ. This is an open-access article distributed under the terms of the Creative Commons Attribution License, which permits unrestricted use, distribution, and reproduction in any medium, provided the original author and source are credited. 